\title{
Diabetes mellitus and the risk of gastric cancer: a meta-analysis of cohort studies
}

\author{
Zhi-Feng Miao ${ }^{1, *}$, Hao $\mathrm{Xu}^{1, *}$, Ying-Ying $\mathrm{Xu}^{2}$, Zhen-Ning Wang ${ }^{1}$, Ting-Ting Zhao ${ }^{2}$, \\ Yong-Xi Song ${ }^{1}$ and Hui-Mian $X^{1}$ \\ ${ }^{1}$ Department of Surgical Oncology, First Hospital of China Medical University, Shenyang, Liaoning Province, China \\ ${ }^{2}$ Department of Breast Surgery, First Hospital of China Medical University, Shenyang, Liaoning Province, China \\ * These authors have contributed equally to this article
}

Correspondence to: Hui-Mian Xu, email: 13898829926@163.com

Keywords: gastric cancer, diabetes mellitus, meta-analysis, gender, prognosis

Received: August 10, $2016 \quad$ Accepted: March 14, 2017

Published: March 22, 2017

Copyright: Miao et al. This is an open-access article distributed under the terms of the Creative Commons Attribution License 3.0 (CC BY 3.0), which permits unrestricted use, distribution, and reproduction in any medium, provided the original author and source are credited.

\section{ABSTRACT}

Studies examining the relationship between diabetes mellitus (DM) and the risk of gastric cancer incidence or gastric cancer mortality have produced inconsistent results. The purpose of this study was to evaluate the evidence regarding the relationship between DM and subsequent gastric cancer incidence or gastric cancer mortality risk on the basis of cohort studies. A systematic search of articles in PubMed, EmBase, the Cochrane Library, and reference lists was conducted to identify relevant literature. Twenty-two cohort studies reporting data on $8,559,861$ participants were included in the study. Overall, participants with DM had little or no change in the risk of gastric cancer, or gastric cancer mortality. There was no evidence of difference in the RR for gastric cancer between men and women. Participants with DM had a non-significant trend towards an increased risk of gastric cancer mortality in men. There was no significant difference between men and women for this relationship. Finally, although subgroup analysis suggested DM was associated with a significant impact on gastric cancer incidence and gastric cancer mortality risk in several specific populations, a significance based on gender difference was not observed. In conclusion, DM might increase the risk of gastric cancer in men when the study used standard incidence/mortality ratio as effect estimate. Further, DM were associated with higher risk of gastric cancer mortality in men if the mean age at baseline less than $\mathbf{5 5 . 0}$ years, used RR or HR as effect estimate, the study adjusted smoking or not, and the study not adjusted alcohol drinking.

\section{INTRODUCTION}

Diabetes mellitus (DM) is a growing global pandemic afflicting approximately three to four percent of adults worldwide. An estimated 366 million people worldwide will development in DM by 2030 [1-4]. DM may predispose patients to premature illness and death due to the relevant risk of cardiovascular diseases [5-6]. In addition, the relationship between DM and cancer risk has been examined in numerous meta-analyses [7-14]. Epidemiologic studies examining the association between DM and gastric cancer risk have largely been inconclusive and provide conflicting results [15-21], including two meta-analyses of the relationship between DM and the risk of gastric cancer [22-23]. Furthermore, whether these relationships differ according to gender in specific subpopulations remains controversial.

In 2012 alone, there were approximately 952,000 gastric cancer cases and 723,000 deaths from gastric cancer worldwide, accounting for $6.8 \%$ of the total cancer cases and $8.8 \%$ of all cancer deaths [24]. Several metaanalyses have indicated that numerous lifestyle factors might play beneficial or harmful impacts on the risk of gastric cancer [25-27]. Yang et al suggested that being overweight or obese associates with an increased risk of gastric cancer and the strength of this relationship 
increases with increasing body mass index (BMI) [28]. It is also worth noting that increased BMI is associated with an increased risk of DM [29]. Clarifying the potential role that DM plays on the risk of gastric cancer is particularly important in the DM populations, as it has not been definitively determined. Hence, the role of DM on the risk of gastric cancer incidence or mortality still needs further evaluation and discussion. Here we attempted a large-scale examination of the available cohort studies to determine the association between DM and the incidence of gastric cancer or gastric cancer mortality. Furthermore, we also evaluated gender differences in this relationship in patients with different baseline characteristics.

\section{RESULTS}

\section{Literature search}

The process of study selection is presented as a flow chart in Figure 1. A total of 2,130 articles from the initial search were identified and screened, of which 2096 were excluded due to being irrelevant, reviews, letters to the editor, having a case control design, producing no desirable outcomes, or including participants with other diseases. A total of 34 studies were reviewed in detail, and 4 without gastric cancer incidence or mortality outcomes were ruled out and another 8 studies were excluded as being different publications of the same sample of participants, thereby including main results that had already been reviewed [30-37]. Ultimately, 22 studies were eligible for the final pooled analysis [15-21, 49-63]. A manual search of the reference lists of these studies did not yield any new eligible studies. The general characteristics of the included studies are presented in Table 1.

\section{Study characteristics}

The 22 included studies covered a total of 8,559,861 individuals and reported 13,538 new gastric cancer cases and 2,140 deaths due to gastric cancer. The sample size for each individual study was $1,135-4,501,578$ participants, while the follow-up period for participants was 3.9-25.0 years. Seven studies were conducted in Asia [16, 20, 5052, 61, 63], 9 in Europe [15, 17, 19, 21, 53, 54, 56, 58, $60]$, and 6 in the USA $[18,49,55,57,59,62] .4$ studies used self-administered questionnaires [20, 49, 62, 63], 7 studies used self-reporting [16, 18, 50-52, 54, 56], 7 studies used medical records $[15,17,19,21,53,58,61]$, and the remaining 4 studies used blood glucose tests [55, $57,59,60]$ to assess exposure. Eight studies used SIR/ SMR to evaluate the relationship between DM and gastric cancer incidence or mortality [15, 17, 19, 52-55, 59], and the remaining 14 studies used OR, RR or HR to calculate this association [16, 18, 20, 21, 49-51, 56-58, 60-63]. Fourteen studies evaluated the relationship between DM

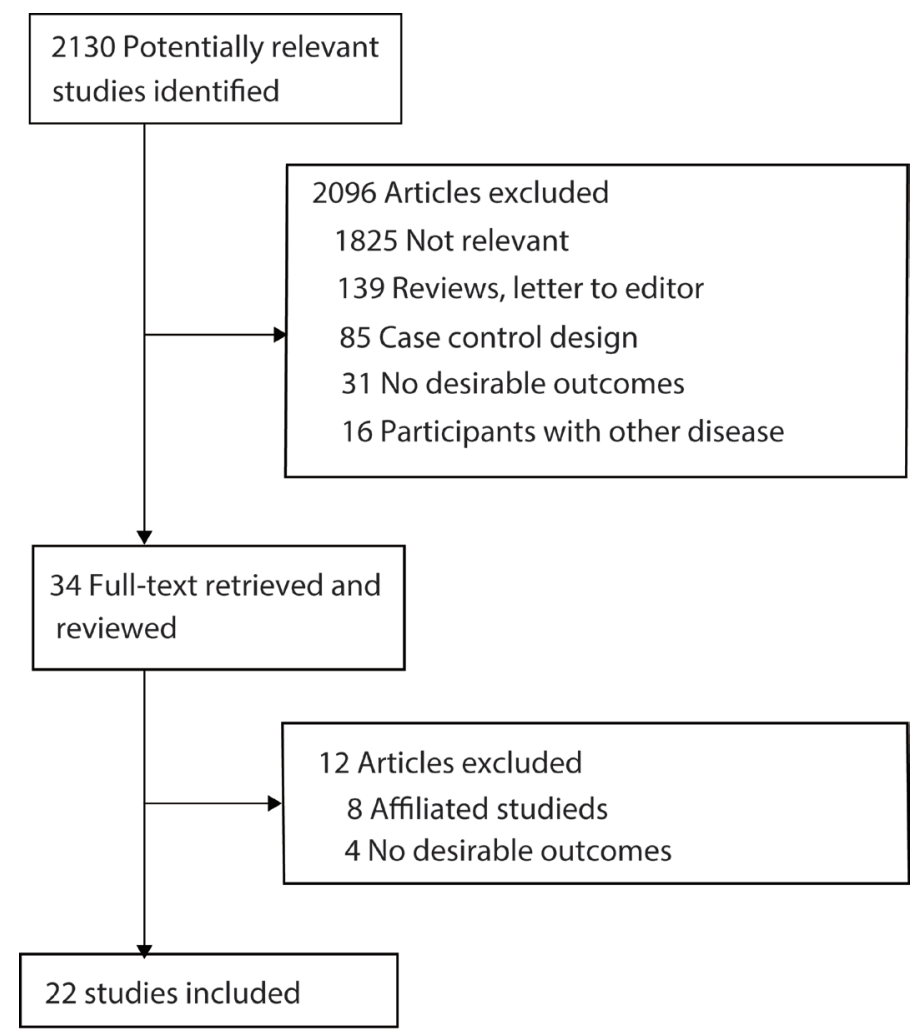

Figure 1: Flow diagram of the literature search and trials selection process. 
Table 1: Baseline characteristics of studies included in the systematic review and meta-analysis

\begin{tabular}{|c|c|c|c|c|c|c|c|c|c|c|c|c|}
\hline Study & Place & $\begin{array}{l}\text { Assessment of } \\
\text { exposure }\end{array}$ & $\begin{array}{l}\text { Sample } \\
\text { size }\end{array}$ & Age at baseline & Gender (M/F) & $\begin{array}{l}\text { Percentage of } \\
\text { overweight } \\
(\%)\end{array}$ & $\begin{array}{l}\text { Gastric } \\
\text { cancer } \\
\text { cases }\end{array}$ & $\begin{array}{l}\text { Death } \\
\text { due to } \\
\text { gastric } \\
\text { cancer } \\
\text { cases }\end{array}$ & $\begin{array}{l}\text { Effect } \\
\text { estimate }\end{array}$ & $\begin{array}{l}\text { Follow- } \\
\text { up (year) }\end{array}$ & Adjusted factors & $\begin{array}{l}\text { NOS } \\
\text { score }\end{array}$ \\
\hline Wideroff L 1997 [15] & Denmark & $\begin{array}{|ll|}\text { Danish } & \text { Cancer } \\
\text { Registry } & \\
\end{array}$ & 109581 & $\begin{array}{c}64.0 \text { for men and } \\
69.0 \text { for women }\end{array}$ & $54571 / 55010$ & NA & 319 & NA & SIR & 17.0 & Age, sex, calendar year & 6 \\
\hline CPS II 2004 [49] & USA & $\begin{array}{l}\text { Self administered } \\
\text { questionnaire }\end{array}$ & 1056243 & 57.0 & $467922 / 588321$ & 48.9 & NA & 109 & RR & 12.5 & $\begin{array}{l}\text { Age, sex, race, } \\
\text { education, family } \\
\text { history, BMI, PA, } \\
\text { smoking, alcohol, diet }\end{array}$ & 8 \\
\hline NHIC 2005 [16] & Korea & $\begin{array}{l}\text { Self-report and } \\
\text { blood } \\
\text { glucose levels }\end{array}$ & 1298385 & 47.0 & $829770 / 468615$ & NA & 1120 & 511 & HR & 10.0 & Age, smoking, alcohol & 9 \\
\hline JPHC 2006 [50] & Japan & Self-report & 97771 & $\begin{array}{l}51.4 \text { for men and } \\
51.8 \text { for women }\end{array}$ & $46548 / 51223$ & 27.3 & 1339 & NA & HR & 14.0 & $\begin{array}{l}\text { Age, study area, VD, } \\
\text { smoking, alcohol, } \\
\text { BMI, PA, vegetable } \\
\text { and coffee intake }\end{array}$ & 8 \\
\hline MHS 2010 [51] & Israel & $\begin{array}{l}\text { Self-report or blood } \\
\text { glucose level }\end{array}$ & 100595 & 61.6 & $52913 / 47682$ & 79.4 & 307 & NA & HR & 8.0 & $\begin{array}{l}\text { Age, region, SES } \\
\text { level, use of healthcare } \\
\text { services, BMI, and } \\
\text { history of VD }\end{array}$ & 7 \\
\hline $\begin{array}{l}\text { Hemminki K } 2010 \\
{[17]}\end{array}$ & Sweden & Medical records & 125126 & $>39.0$ & NA & NA & 469 & NA & SIR & 15.0 & NA & 5 \\
\hline $\begin{array}{l}\text { NIH-AARP Diet and } \\
\text { Health } \\
\text { [18] }\end{array}$ & USA & Self-report & 469448 & 62.0 & $280883 / 188565$ & 64.6 & 631 & NA & HR & 10.0 & $\begin{array}{l}\text { Age, sex, calories, } \\
\text { alcohol, smoking, fruit } \\
\text { consumption, ethnicity, } \\
\text { education, and PA }\end{array}$ & 8 \\
\hline Tseng CH 2011 [52] & Taiwan & Self-report & 88694 & $>25.0$ & $40799 / 47895$ & NA & NA & 1049 & SMR & 12.0 & Age and sex & 6 \\
\hline $\begin{array}{l}\text { Verona Diabetes } \\
\text { Study } 2003 \text { [53] }\end{array}$ & Italy & Medical records & 7148 & 67.0 & $3366 / 3782$ & 70.7 & NA & 48 & SMR & 10.0 & Age, smoking, BMI & 7 \\
\hline $\begin{array}{l}\text { Swerdlow AJ } 2005 \\
\text { [54] }\end{array}$ & UK & Self-report & 5066 & $30-49$ & $2944 / 2122$ & NA & 12 & 9 & SIR & 18.0 & $\begin{array}{l}\text { Age, sex, calendar } \\
\text { year, } \\
\text { residence }\end{array}$ & 6 \\
\hline Kessler II 1970 [55] & USA & Blood glucose test & 218313 & $40-59$ & $96010 / 122313$ & NA & NA & 98 & SMR & 10.0 & Age, sex & 6 \\
\hline HIC 2009 [56] & Scotland & Self-report & 28731 & 62.0 & $15227 / 13504$ & NA & NA & 62 & $\mathrm{RR}$ & 3.9 & Deprivation decile & 7 \\
\hline $\begin{array}{l}\text { U.S. Veterans } 2010 \\
\text { [57] }\end{array}$ & USA & Discharge diagnosis & 4501578 & 59.1 & $4501578 / 0$ & 5.7 & 7515 & NA & $\mathrm{RR}$ & 10.5 & $\begin{array}{l}\text { Age, time, latency, } \\
\text { race, number of } \\
\text { visits,alcohol, obesity } \\
\text { and COPD }\end{array}$ & 8 \\
\hline $\begin{array}{l}\text { Zendehdel K } 2003 \\
\text { [19] }\end{array}$ & Sweden & Medical records & 29187 & 38.7 & $14864 / 14323$ & NA & 10 & NA & SIR & 14.4 & $\begin{array}{l}\text { Excluding the } 1 \text { st } \\
\text {-year of follow-up }\end{array}$ & 7 \\
\hline $\begin{array}{l}\text { Koskinen } \\
\text { [58] }\end{array}$ & Finland & Census records & 58000 & $30-74$ & $24000 / 34000$ & NA & NA & 73 & $\mathrm{RR}$ & 5.0 & Age & 6 \\
\hline JACC 2006 [20] & Japan & \begin{tabular}{|l|} 
Self administered \\
questionnaire
\end{tabular} & 56881 & $40-79$ & $23378 / 33503$ & 19.8 & 631 & NA & $\mathrm{RR}$ & $18.0-20.0$ & $\begin{array}{l}\text { Age, BMI, smoking, } \\
\text { and drinking }\end{array}$ & 8 \\
\hline $\begin{array}{l}\text { Ragozzino M } 1982 \\
\text { [59] }\end{array}$ & USA & Blood glucose levels & 1135 & 61.0 & $602 / 533$ & NA & 8 & NA & SIR & 8.6 & Age, sex & 7 \\
\hline Adami HO 1991 [21] & Sweden & Medical records & 51008 & NA & $23146 / 27862$ & NA & 159 & NA & $\mathrm{RR}$ & 5.2 & Age, sex & 6 \\
\hline $\begin{array}{l}\text { Whitehall study } 2004 \\
{[60]}\end{array}$ & UK & $\begin{array}{l}\text { Oral glucose } \\
\text { tolerance test }\end{array}$ & 18006 & 51.5 & $18006 / 0$ & NA & NA & 162 & HR & 25.0 & $\begin{array}{l}\text { Age, employment, } \\
\text { smoking, SBP, PA, } \\
\text { disease history }\end{array}$ & 7 \\
\hline NHIRD 2013 [61] & Taiwan & Medical records & 98125 & 56.0 & $54675 / 43450$ & NA & 263 & NA & HR & 5.5 & $\begin{array}{l}\text { Age, sex, CGD, } \\
\text { pneumoconiosis }\end{array}$ & 8 \\
\hline $\begin{array}{l}\text { Strong Heart Study } \\
2015 \text { [62] }\end{array}$ & USA & $\begin{array}{l}\text { Self administered } \\
\text { questionnaire }\end{array}$ & 4419 & 55.1 & $1794 / 2625$ & 50.9 & NA & 19 & HR & 20.0 & $\begin{array}{l}\text { Age, sex, center, BMI, } \\
\text { education, drinking } \\
\text { status and smoking }\end{array}$ & 8 \\
\hline Xu HL 2015 [63] & China & $\begin{array}{l}\text { Self administered } \\
\text { questionnaire }\end{array}$ & 136421 & 53.4 & $61480 / 74941$ & NA & 755 & NA & HR & $\begin{array}{l}7.5 \text { for } \\
\text { men and } \\
13.2 \text { for } \\
\text { women }\end{array}$ & $\begin{array}{l}\text { Age, sex, education, } \\
\text { income, BMI, CGD, } \\
\text { family history of } \\
\text { stomach cancer, PA, } \\
\text { EI, smoking, tea, } \\
\text { alcohol, vegetable, red } \\
\text { meat, and fruit intake }\end{array}$ & 8 \\
\hline
\end{tabular}

Abbreviations: BMI: body mass index; PA: physical activity; VD: vascular disease; EI: energy intake; CGD: chronic gastric disease; NA: not available.

and the incidence of gastric cancer [15-21, 50, 51, 54, $57,59,61,63]$, and ten studies evaluated the relationship between DM and the risk of gastric cancer mortality [16, $49,52-56,58,60,62]$. Study quality was evaluated using the NOS score (Table 1) [39]. Overall, 1 study had a score of 9 [16], 8 studies had a score of $8[18,20,49,50,57$, 61-63], 6 studies had a score of $7[19,51,53,56,59,60]$, 6 studies had a score of $6[15,21,52,54,55,58]$, and the remaining 1 study had a score of 5 [17].

\section{DM and the risk of gastric cancer incidence or mortality}

A total of 15 studies reported an association between DM and the incidence of gastric cancer [15-21, 50, 51, $54,56,57,59,61,63]$. The summary RR showed that participants with DM were not associated with a change in gastric cancer risk (RR: 1.10 ; 95\%CI: 0.94-1.29; $P$ $=0.229$; Figure $2 \mathrm{~A}$ ), but substantial heterogeneity was 
Table 2: Subgroup analysis of relative risk (ratios) for gastric cancer in men and women

\begin{tabular}{|c|c|c|c|c|c|c|c|}
\hline Subgroup & $\begin{array}{l}\text { Stratified } \\
\text { analyses }\end{array}$ & Sex & $\mathrm{RR}$ and $95 \% \mathrm{CI}$ & $P$ value & \begin{tabular}{|l|l} 
I-square & and \\
$P$ value for \\
heterogeneity
\end{tabular} & $\begin{array}{l}\mathrm{RRR} \\
95 \% \mathrm{CI}\end{array}$ & \begin{tabular}{|l}
$P$ value for \\
interaction \\
test
\end{tabular} \\
\hline \multirow{4}{*}{ Country } & \multirow{2}{*}{$\begin{array}{l}\text { Western } \\
\text { countries }\end{array}$} & Men & $0.98(0.84-1.15)$ & 0.817 & $73.3 \%(0.005)$ & \multirow{2}{*}{$0.92(0.75-1.14)$} & \multirow{2}{*}{0.466} \\
\hline & & Women & $1.06(0.92-1.22)$ & 0.400 & $0.0 \%(0.456)$ & & \\
\hline & \multirow{2}{*}{$\begin{array}{l}\text { Eastern } \\
\text { countries }\end{array}$} & Men & $1.02(0.86-1.20)$ & 0.817 & $46.3 \%(0.097)$ & \multirow{2}{*}{$0.97(0.72-1.32)$} & \multirow{2}{*}{0.851} \\
\hline & & Women & $1.05(0.82-1.36)$ & 0.690 & $55.0 \%(0.049)$ & & \\
\hline \multirow{4}{*}{$\begin{array}{l}\text { Age at } \\
\text { baseline }\end{array}$} & \multirow{2}{*}{$\geq 55$} & Men & $1.06(0.90-1.25)$ & 0.481 & $64.4 \%(0.015)$ & \multirow{2}{*}{$0.95(0.77-1.19)$} & \multirow{2}{*}{0.679} \\
\hline & & Women & $1.11(0.96-1.28)$ & 0.175 & $0.0 \%(0.922)$ & & \\
\hline & \multirow{2}{*}{$<55$} & Men & $1.06(0.93-1.22)$ & 0.373 & $26.5 \%(0.257)$ & \multirow{2}{*}{$0.91(0.67-1.24)$} & \multirow{2}{*}{0.566} \\
\hline & & Women & $1.16(0.88-1.53)$ & 0.306 & $59.0(0.087)$ & & \\
\hline \multirow{4}{*}{$\begin{array}{l}\text { Effect } \\
\text { estimate }\end{array}$} & \multirow{2}{*}{ SIR/SMR } & Men & $1.20(1.05-1.36)$ & 0.007 & $0.0 \%(0.666)$ & \multirow{2}{*}{$1.09(0.88-1.35)$} & \multirow{2}{*}{0.420} \\
\hline & & Women & $1.10(0.93-1.30)$ & 0.264 & $0.0 \%(0.933)$ & & \\
\hline & \multirow{2}{*}{ OR, RR, or HR } & Men & $0.97(0.87-1.09)$ & 0.598 & $66.5 \%(0.002)$ & \multirow{2}{*}{$0.92(0.74-1.16)$} & \multirow{2}{*}{0.487} \\
\hline & & Women & $1.05(0.87-1.28)$ & 0.594 & $49.4 \%(0.054)$ & & \\
\hline \multirow{4}{*}{$\begin{array}{l}\text { Follow-up } \\
\text { duration } \\
\text { (yr) }\end{array}$} & \multirow{2}{*}{$\geq 15$} & Men & $0.99(0.61-1.61)$ & 0.957 & $73.2 \%(0.053)$ & \multirow{2}{*}{$1.65(0.38-7.21)$} & \multirow{2}{*}{0.506} \\
\hline & & Women & $0.60(0.15-2.43)$ & 0.477 & $82.7 \%(0.016)$ & & \\
\hline & \multirow{2}{*}{$<15$} & Men & $0.98(0.88-1.10)$ & 0.756 & $64.0(0.005)$ & \multirow{2}{*}{$0.91(0.76-1.08)$} & \multirow{2}{*}{0.273} \\
\hline & & Women & $1.08(0.95-1.24)$ & 0.248 & $13.2 \%(0.327)$ & & \\
\hline \multirow{4}{*}{$\begin{array}{l}\text { Adjusted } \\
\text { BMI }\end{array}$} & $V_{-1}$ & Men & $0.98(0.83-1.16)$ & 0.826 & $42.5 \%(0.138)$ & 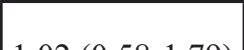 & Pि \\
\hline & Yes & Women & $0.96(0.56-1.63)$ & 0.870 & $70.3 \%(0.018)$ & $1.02(0.58-1.79)$ & 0.942 \\
\hline & $v_{T}$ & Men & $1.01(0.87-1.18)$ & 0.889 & $68.5 \%(0.007)$ & $\log \theta \sin$ & 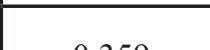 \\
\hline & No & Women & $1.10(0.99-1.21)$ & 0.067 & $0.0 \%(0.660)$ & $0.92(0.1 /-1.10)$ & 0.359 \\
\hline & Vea & Men & $1.03(0.90-1.18)$ & 0.690 & $27.0(0.241)$ & $002(0,66120)$ & 0666 \\
\hline Adjusted & Yes & Women & $1.11(0.81-1.51)$ & 0.509 & $65.4 \%(0.021)$ & $0.93(0.66-1.30)$ & 0.666 \\
\hline & $N$ & Men & $1.00(0.85-1.18)$ & 0.995 & $74.5 \%(0.001)$ & 7010 & 0712 \\
\hline & No & Women & $1.04(0.91-1.18)$ & 0.592 & $0.0 \%(0.816)$ & $0.96(0 . / 8-1.19)$ & 0.113 \\
\hline & Yot & Men & $1.00(0.89-1.12)$ & 0.952 & $61.5 \%(0.024)$ & $000 \times 0-6 \quad 120$ & 0520 \\
\hline Adjusted & Yes & Women & $1.11(0.81-1.51)$ & 0.509 & $65.4 \%(0.021)$ & $0.90(0.65-1.26)$ & 0.538 \\
\hline drinking & $N$ & Men & $1.02(0.78-1.33)$ & 0.879 & $76.5 \%(0.002)$ & & 0800 \\
\hline & No & Women & $1.04(0.91-1.18)$ & 0.592 & $0.0 \%(0.816)$ & $(0 . / 3-1.3)-3$ & 0.898 \\
\hline & & Men & $0.98(0.80-1.19)$ & 0.802 & $0.0 \%(0.498)$ & & \\
\hline Adjusted & Yes & Women & $1.27(0.82-1.97)$ & 0.284 & $63.0 \%(0.067)$ & $0.77(0.48-1.25)$ & 0.291 \\
\hline $\begin{array}{l}\text { physical } \\
\text { activity }\end{array}$ & & Men & $1.01(0.89-1.14)$ & 0.913 & $75.6 \%(<0.001)$ & & \\
\hline & No & Women & $1.04(0.91-1.20)$ & 0.556 & $27.8 \%(0.216)$ & $0.91(0.81-1.17)$ & $0.15 /$ \\
\hline
\end{tabular}

detected $(P<0.001)$. Furthermore, a total of 9 studies reported an association between DM and the risk of gastric cancer mortality $[16,49,52-55,58,60,62]$. There was no significant association between DM patients and participants without DM for gastric cancer mortality across all studies (RR: 1.28 ; 95\%CI: 0.93-1.76; $P=0.123$; Figure 2B). Substantial heterogeneity was observed in the magnitude of the effect across the studies $(P<0.001)$.

\section{DM and the risk of gastric cancer incidence in men and women}

There were 11 studies with data available for men $[15,16,18,20,21,50,51,57,59,61,63]$ and 10 studies for women $[15,16,18,20,21,50,51,59,61,63]$. The summary analysis results for men and women with or without DM showed that DM was not associated with 
the risk of gastric cancer incidence in men (RR: 1.00; 95\%CI: $0.90-1.11 ; P=0.972$; Figure $3 \mathrm{~A}$ ) or in women (RR: $1.07 ; 95 \%$ CI: 0.93-1.22; $P=0.368$; Figure 3B). Gender difference was not significantly associated with the relationship between DM and gastric cancer incidence (RRR: 0.93; 95\%CI: 0.77-1.14; $P=0.495$ ). Furthermore, we noted potential evidence of heterogeneity for gastric cancer in men (I-square: $67.0 \% ; P=0.001$ ), and mild heterogeneity for gastric cancer in women (I-square: $35.1 \% ; P=0.127$ ). Once sensitivity analyses were conducted for men and women, we noted that the conclusion was not affected by the systematic exclusion of any one specific study from the pool (Supplemental 2: Tables S1 and S2). However, women were found to have increased risk for gastric cancer when excluding the JACC study [20] (RR: 1.09; 95\%CI: 0.99-1.20; P P=0.066; I-square: $0.9 \% ; P$ value for heterogeneity: 0.426$)$, which illustrated the incidence of gastric cancer is gradually decreasing in Japan recently.

\section{DM and the risk of gastric cancer mortality in men and women}

The breakdown for the number of studies available for mortality associations with men and women was
$6[16,49,52,53,58,60]$ and 5 studies $[16,49,52,53$, 58], respectively. The summary analysis results for men and women with or without DM indicated that DM was not associated with the risk of gastric cancer mortality in men (RR: 1.33 ; 95\%CI: 0.93-1.89; $P=0.114$; Figure 4A) or women (RR: 1.40 ; 95\%CI: $0.95-2.06 ; P=0.085$; Figure 4B). The RRR indicated that no gender difference existed for this relationship (RRR: 0.95 ; 95\%CI: $0.56-$ $1.61 ; P=0.848)$. Substantial heterogeneity was detected for gastric cancer mortality in men and women (men: I-square: $96.0 \%, P<0.001$; women: $93.1 \%, P<0.001$ ). According to sensitivity analyses, DM was associated with an increased risk of gastric cancer mortality in men when excluding the Tseng study, the study specific reported SMR at different age stages, and the effect estimate was inconceivable higher in DM patients aged 25-64 years [52] (RR: 1.17; 95\%CI: 1.07-1.28; $P<0.001$; I-square: $1.2 \% ; P$ value for heterogeneity: 0.400 ; Supplemental 2: Table S3), which specifically included a wide range of participants and had a mean age greater than 25.0 years. Similarly, after excluding the Tseng study [52], we noted participants with DM may have an increased risk of gastric cancer mortality in women (RR: 1.21 ; 95\%CI: 1.06-1.40; $P=0.006$; I-square: $0.0 \%$; $P$ value for heterogeneity: 0.533; Supplemental 2: Table S4).

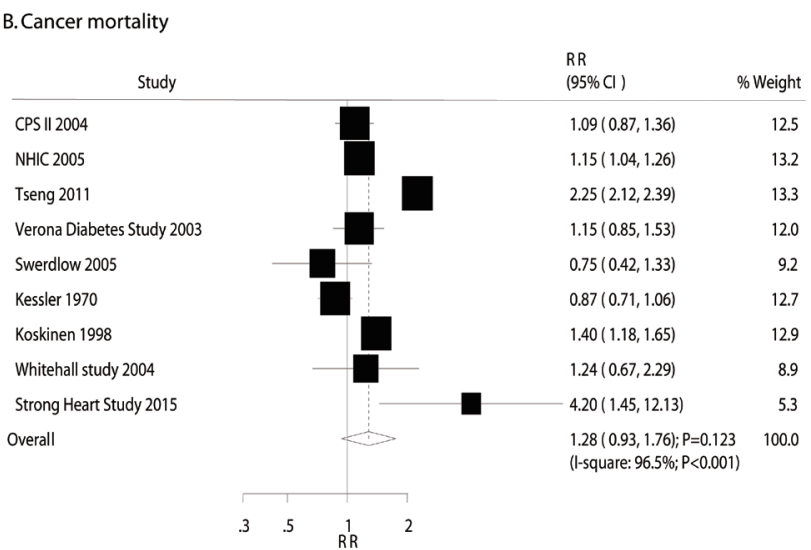

Figure 2: Association of diabetes mellitus with the risk of gastric cancer incidence (A) and mortality (B).

A. Cancer incidence for men

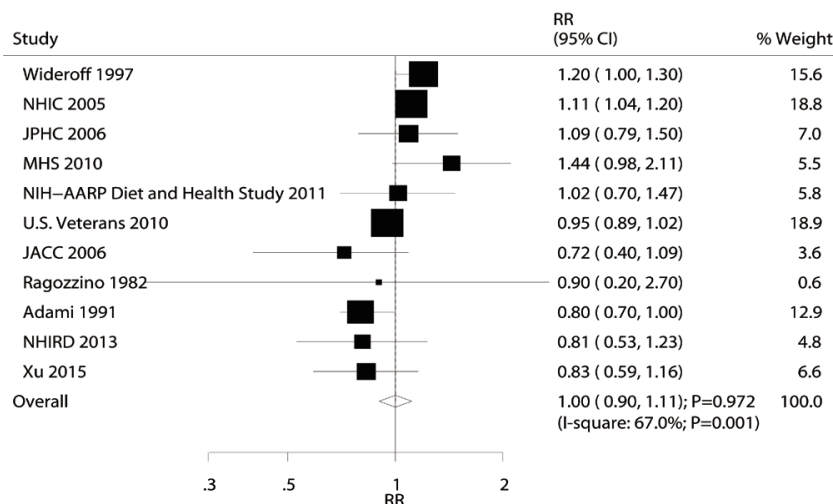

B Cancer incidence for women

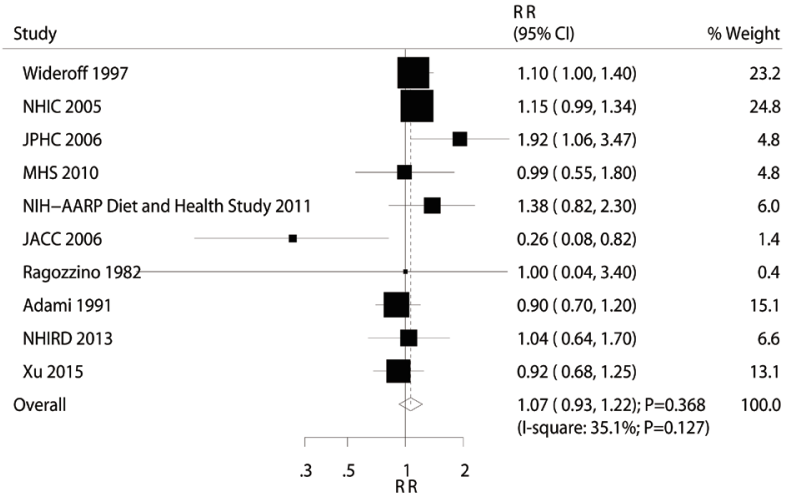

Figure 3: Association of diabetes mellitus with the risk of gastric cancer incidence in men (A) and women (B). 
Table 3: Subgroup analysis of relative risk (ratios) for gastric cancer mortality in men and women

\begin{tabular}{|c|c|c|c|c|c|c|c|}
\hline Subgroup & $\begin{array}{l}\text { Stratified } \\
\text { analyses }\end{array}$ & Sex & RR and $95 \% C I$ & $P$ value & \begin{tabular}{|lr} 
I-square & and \\
$P$ value for \\
heterogeneity
\end{tabular} & RRR and $95 \% \mathrm{CI}$ & \begin{tabular}{|l}
$P$ value for \\
interaction \\
test
\end{tabular} \\
\hline \multirow{4}{*}{ Country } & \multirow{2}{*}{$\begin{array}{l}\text { Western } \\
\text { countries }\end{array}$} & Men & $1.19(0.99-1.43)$ & 0.070 & $24.5 \%(0.264)$ & \multirow{2}{*}{$0.91(0.70-1.18)$} & \multirow{2}{*}{0.467} \\
\hline & & Women & $1.31(1.09-1.57)$ & 0.004 & $0.0 \%(0.739)$ & & \\
\hline & \multirow{2}{*}{\begin{tabular}{|l} 
Eastern \\
countries
\end{tabular}} & Men & $1.61(0.85-3.03)$ & 0.144 & $99.0 \%(<0.001)$ & \multirow{2}{*}{$1.01(0.38-2.66)$} & \multirow{2}{*}{0.980} \\
\hline & & Women & $1.59(0.77-3.31)$ & 0.212 & $97.4 \%(<0.001)$ & & \\
\hline \multirow{4}{*}{$\begin{array}{l}\text { Age at } \\
\text { baseline }\end{array}$} & \multirow{2}{*}{$\geq 55$} & Men & $1.04(0.84-1.28)$ & 0.737 & $0.0 \%(0.503)$ & \multirow{2}{*}{$0.85(0.61-1.20)$} & \multirow{2}{*}{0.359} \\
\hline & & Women & $1.22(0.93-1.59)$ & 0.151 & $0.0 \%(0.773)$ & & \\
\hline & \multirow{2}{*}{$<55$} & Men & $1.16(1.05-1.29)$ & 0.004 & $0.0 \%(0.834)$ & \multirow{2}{*}{$1.06(0.84-1.35)$} & \multirow{2}{*}{0.612} \\
\hline & & Women & $1.09(0.88-1.36)$ & 0.438 & - & & \\
\hline \multirow{4}{*}{$\begin{array}{l}\text { Effect } \\
\text { estimate }\end{array}$} & \multirow{2}{*}{ SIR/SMR } & Men & $1.65(0.88-3.11)$ & 0.120 & $90.2 \%(0.001)$ & \multirow{2}{*}{$0.98(0.39-2.46)$} & \multirow{2}{*}{0.959} \\
\hline & & Women & $1.69(0.86-3.32)$ & 0.127 & $87.9 \%(0.004)$ & & \\
\hline & \multirow{2}{*}{$\begin{array}{l}\text { OR, RR, or } \\
\text { HR }\end{array}$} & Men & $1.17(1.04-1.33)$ & 0.012 & $25.9 \%(0.257)$ & \multirow{2}{*}{$0.96(0.79-1.17)$} & \multirow{2}{*}{0.674} \\
\hline & & Women & $1.22(1.05-1.42)$ & 0.009 & $6.4 \%(0.343)$ & & \\
\hline \multirow{4}{*}{$\begin{array}{l}\text { Follow-up } \\
\text { duration } \\
\text { (yr) }\end{array}$} & \multirow{2}{*}{$\geq 15$} & Men & $1.24(0.67-2.29)$ & 0.493 & - & \multirow{2}{*}{ - } & \multirow{2}{*}{-} \\
\hline & & Women & - & - & - & & \\
\hline & \multirow{2}{*}{$<15$} & Men & $1.34(0.92-1.96)$ & 0.129 & $96.7 \%(<0.001)$ & \multirow{2}{*}{$0.96(0.56-1.64)$} & \multirow{2}{*}{0.874} \\
\hline & & Women & $1.40(0.95-2.06)$ & 0.085 & $97.1 \%(<0.001)$ & & \\
\hline \multirow{4}{*}{$\begin{array}{l}\text { Adjusted } \\
\text { BMI }\end{array}$} & Yeo & Men & $1.04(0.84-1.28)$ & 0.737 & $0.0 \%(0.503)$ & $085(061120)$ & 0350 \\
\hline & Yes & Women & $1.22(0.93-1.59)$ & 0.151 & $0.0 \%(0.773)$ & $0.85(0.61-1.20)$ & 0.359 \\
\hline & $N$ & Men & $1.48(0.96-2.28)$ & 0.075 & $97.1 \%(<0.001)$ & $007(050100$ & ר0? \\
\hline & NO & Women & $1.53(0.92-2.53)$ & 0.100 & $95.7 \%(<0.001)$ & $0.91(0.50-1.88)$ & 0.922 \\
\hline & Yes & Men & $1.14(1.03-1.25)$ & 0.008 & $0.0 \%(0.498)$ & $100(082-123)$ & 100 \\
\hline Adjusted & Yes & Women & $1.14(0.95-1.36)$ & 0.165 & $0.0 \%(0.494)$ & & \\
\hline smoking & No & Men & $1.58(1.04-2.39)$ & 0.032 & $91.1 \%(<0.001)$ & $0.99(0.54-182)$ & 0.968 \\
\hline & No & Women & $1.60(1.02-2.50)$ & 0.039 & $90.5 \%(<0.001)$ & $0.99(0.34-1.82)$ & 0.968 \\
\hline & & Men & $1.12(0.98-1.27)$ & 0.095 & $23.9 \%(0.252)$ & & \\
\hline & Yes & Women & $1.14(0.95-1.36)$ & 0.165 & $0.0 \%(0.494)$ & $0.98(0.79-1.23)$ & 0.875 \\
\hline $\begin{array}{l}\text { alcohol } \\
\text { drinking }\end{array}$ & T & Men & $1.51(1.04-2.21)$ & 0.031 & $88.1 \%(<0.001)$ & & \\
\hline & & Women & $1.60(1.02-2.50)$ & 0.039 & $90.5 \%(<0.001)$ & & \\
\hline & & Men & $1.02(0.81-1.29)$ & 0.853 & $0.0 \%(0.506)$ & & \\
\hline Adjusted & & Women & $1.25(0.90-1.73)$ & 0.181 & - & $0.02(0.00-1.22)$ & 0.020 \\
\hline activity & & Men & $1.45(0.95-2.20)$ & 0.085 & $97.1 \%(<0.001)$ & & \\
\hline & INO & Women & $1.44(0.92-2.24)$ & 0.108 & $94.2 \%(<0.001)$ & $1.01(0.35-1.86)$ & 0.982 \\
\hline
\end{tabular}

\section{Subgroup analysis}

Substantial heterogeneity was detected for gastric cancer incidence and mortality in men and women. We therefore performed subgroup analyses to minimize heterogeneity and evaluate the potential role of DM on the progression of gastric cancer among the included studies. First, DM was associated with an increased risk of gastric cancer incidence in men if the study used SIR/SMR as an effect estimate index (Table 2). Second, participants with DM showed an increased risk of gastric cancer mortality if 
the study was conducted on women in Western countries, the study used OR, RR, or HR as an effect estimate index, and the study was not adjusted for smoking or alcohol consumption (Table 3 ). Third, DM significantly increased the risk of gastric cancer mortality in men if the mean age was less than 55 years, the study used OR, RR, or HR as an effect estimate index, and the study was not adjusted for alcohol consumption (Table 3). There were no gender differences for gastric cancer incidence and gastric cancer mortality in specific subsets.

\section{Publication bias}

Review of the funnel plots could not rule out the potential for publication bias for gastric cancer incidence and gastric cancer mortality (Figure 5). The Egger [47] and Begg tests [48] results showed no evidence of publication bias for gastric cancer incidence $(P$ value for Egger: 0.892; $P$ value for Begg: 0.621$)$ or gastric cancer mortality ( $P$ value for Egger: $0.148 ; P$ value for Begg: 0.348).

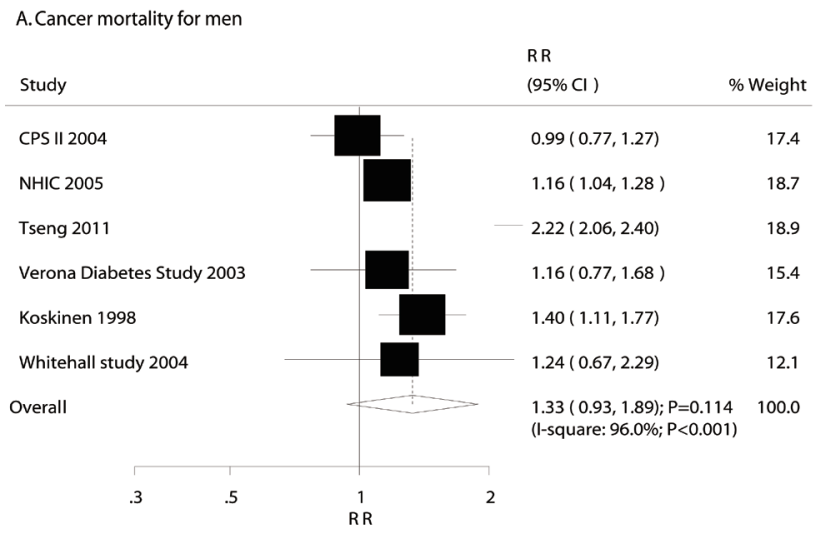

\section{DISCUSSION}

Our current study was based on cohort studies and explored all possible correlations between DM and the outcomes of gastric cancer incidence and gastric cancer mortality. This large quantitative study included 8,559,861 participants from 22 cohort studies with a broad range of populations. The findings from our study indicate that DM has no overall significant impact on the risk of gastric cancer incidence and gastric cancer mortality. Subgroup analyses suggested mean age at baseline, effect estimate, adjusted smoking, alcohol drinking or not might affect the incidence of gastric cancer mortality in men, and Country, effect estimate, adjusted smoking, alcohol drinking or not were affect gastric cancer mortality in women. However, there were no gender differences between men and women for any correlations of DM and gastric cancer.

The methodological evaluation of each included study was limited by the representativeness of the exposed cohort, selection of the non-exposed cohort, ascertainment of DM, demonstration that outcomes were not present at

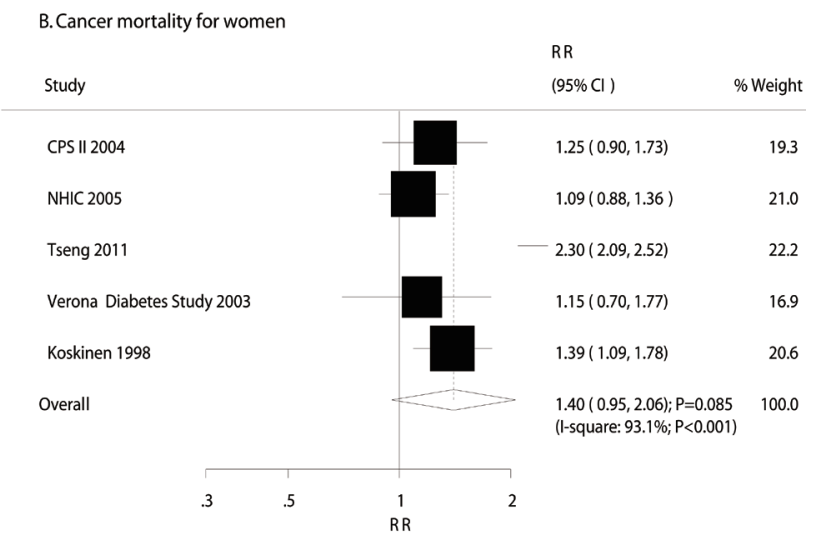

Figure 4: Association of diabetes mellitus with the risk of gastric cancer mortality in men (A) and women (B).

A. Cancer incidence

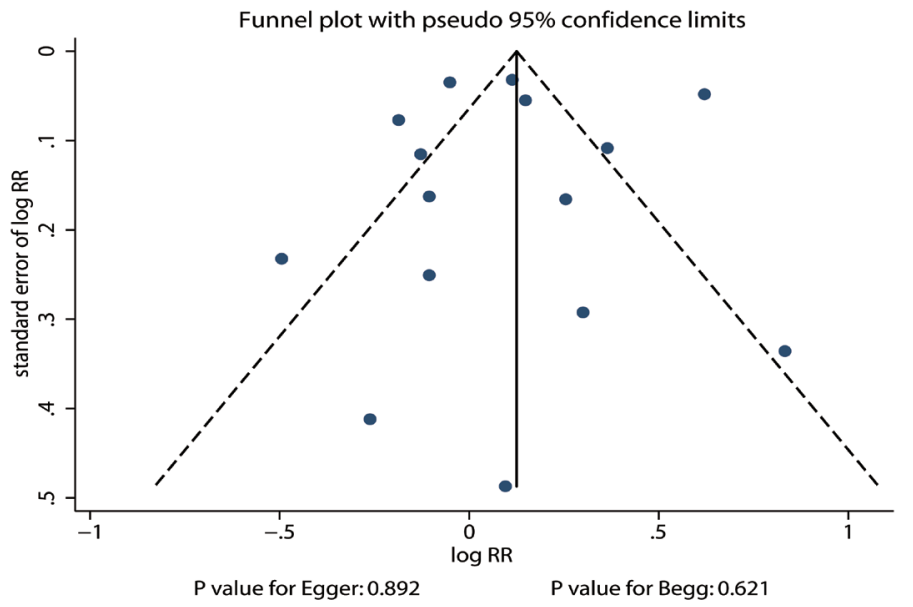

B. Cancer mortality

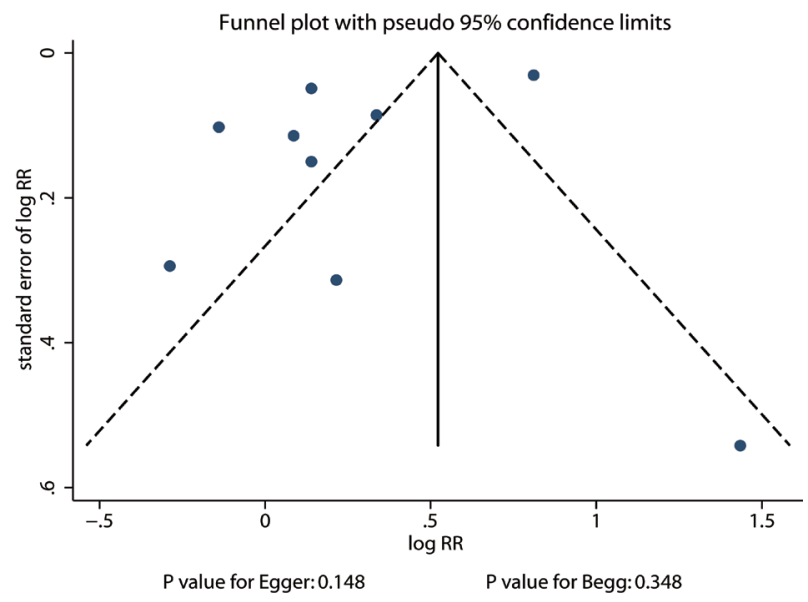

Figure 5: Funnel plots for gastric cancer incidence (A) and gastric cancer mortality (B). 
the start of study, comparability on the basis of the design or analysis, assessment of outcome, adequate follow-up duration, and adequate follow-up rate. Our meta-analysis of cohort studies provides unclear results for the selection of the non-exposed cohort if the study reported SIR/SMR as the effect estimate, which contributed to heterogeneity in overall analysis. Therefore, the summary results might be biased due to different effect estimate indexes.

A previous meta-analysis suggested that DM patients had a similar risk of gastric cancer incidence and substantial heterogeneity was observed. Furthermore, subgroup analyses indicated DM significantly increased the risk of gastric cancer in men, whereas it had no effect in women [23]. However, another meta-analysis suggested that total participants with DM have an increased risk of gastric cancer, and are positively associated with gastric cancer mortality [22]. The inherent limitation of those previous meta-analyses is that case control studies were included and various confounding factors might be biasing the results, as several important confounders cannot be adjusted. We therefore conducted this study to evaluate the relationship between DM and the risk of gastric cancer incidence or mortality on the basis of gender.

Most of our findings were in agreement with a recently published large cohort study conducted in the UK [54]. This prospective study included 28,900 patients with insulin-treated diabetes and found that DM was not associated with gastric cancer incidence or mortality risk. The reason for this could be that the study design used total cancer events as primary outcomes, and the sample size might not have been sufficient to evaluate the relationship between DM and gastric cancer risk. Event rates were lower than expected, which always requires broad confidence intervals, resulting in no statistically significant difference. Chodick et al [51] conducted a cohort study and, after an 8 year follow-up, concluded that there was no significant increase in overall risk of gastric cancer incidence between DM and non-DM participants. $\mathrm{Xu}$ et al [63] did not find any evidence that type $2 \mathrm{DM}$ was associated with an increased risk of gastric cancer either in men or in women. Our current study also indicated that DM has no significant effect on the overall risk of gastric cancer. Yet symptoms of gastric cancer can be hidden and diagnosis might come late in DM patients with gastric cancer, which could incorrectly lend toward this conclusion of non-significant correlations.

There was no significant difference between DM and non-DM participants and the risk of gastric cancer incidence or mortality. However, several studies included in our study reported inconsistent results. Jee et al [16] indicated that elevated fasting serum glucose and DM are independent risk factors for gastric cancer, and the relative risk tends to increase accompanying an increased fasting serum glucose level. Similarly, Lin et al [18] found a significant association between DM and the higher risk of gastric cancer. They explained this relationship saying that
DM patients with hyperglycemia may cause dysregulation of energy balance, which could affect intracellular metabolism and impair immune system and might play an important role in the progression of gastric cancer [64]. Conversely, a significantly reduced risk for gastric cancer following DM was detected in Khan et al and Adami et al $[20,21]$. These could be due to time effects in certain cases, with an early decrease followed by an increased risk.

Subgroup analysis suggested that males with DM were associated with an increased risk of gastric cancer if the study used SIR/SMR as an effect estimate index. Furthermore, participants with DM might have an increased risk of gastric cancer mortality in multiple subsets. It is possible that longer diabetes duration could be associated with insulin resistance and hyperinsulinemia, which might has an effect on promoting cell growth and proliferation. Although an important population-based study compared the incidence of gastric cancer in insulin users and nonusers and showed a lack of association between insulin use and gastric cancer, which might due to DM patients received insulin or not with different DM status [65]. Furthermore, most confounders cannot be adjusted in several studies, which might bias the summary result. Finally, several conclusions may be variable since smaller cohorts were included. Therefore, relative results with a comprehensive review were provided in our study.

We noted higher heterogeneity for the summary results, the reason for this could be the baseline characteristics might affect the relationship between DM and gastric cancer incidence or mortality. Tseng et al indicated hyperglycemia, Helicobacter pylori (HP) infection, high salt intake, medications and comorbidities might play an important role on the risk of gastric cancer. They stated DM patients was associated with higher infection rate, lower eradication rate and higher reinfection rate of HP. Further, salt intake might affect HP infection [66]. However, salt intake and HP infection status were not reported in the studies included in our meta-analysis. In addition, patients in different ethnicities and geographical regions with different levels of salt intake and HP infection, which may affect the relationship between $\mathrm{DM}$ and gastric cancer and contribute to the potential heterogeneity. Furthermore, Tseng et al resulted DM patients received metformin might affect the incidence of gastric cancer [67]. Finally, they indicated DM was contributed a harmful effect on gastric cancer, whereas insulin use has no significant effect on the gastric cancer risk [65]. In this study, mostly studies included could not adjusted antidiabetic drugs, which may introduce potential heterogeneity.

Three strengths of our study should be highlighted. First, only cohort studies were included, which should eliminate uncontrolled biases. Second, the large sample size allowed us to quantitatively assess the association of DM with the risk of gastric cancer and mortality, 
potentially making our findings more robust than those of any individual study. Third, the summary RRR was employed to evaluate gender differences for this relationship.

The limitations of our study are as follows: (1) the adjusted models are different across the included studies, and these factors might play an important role in the development of gastric cancer; (2) the incidence of gastric cancer and mortality was difference, which might introduce uncontrol biases; (3) postmenopausal status in women might affect the incidence of gastric cancer or mortality, whereas the results of stratified analysis in individual study was not available; (4) in a meta-analysis of published studies, publication bias is an inevitable problem; and (5) the analysis used pooled data (individual data were not available), which restricted us from performing a more detailed relevant analysis and obtaining more comprehensive results.

The findings of this study suggest that DM is not associated with overall changes in gastric cancer or mortality risk. Furthermore, subgroup analyses suggested that certain participants (mean age at baseline less than 55.0 , used RR or HR as effect estimate, the study adjusted smoking or not, and the study not adjusted alcohol drinking in men, and the study conducted in Western Countries, used RR or HR as effect estimate, not adjusted smoking or alcohol drinking in women.) with DM may see a higher risk of gastric cancer mortality. Future studies are needed to focus on specific populations and evaluate potential interactions of other important confounders.

\section{MATERIALS AND METHODS}

We followed Preferred Reporting Items for Systematic reviews and Meta-analysis guideline in reporting this systematic review and meta-analysis [38].

\section{Data Sources, Search Strategy, and Selection Criteria}

Literature research was carried out by searching relevant publications via the electronic databases PubMed, EmBase and the Cochrane Library. Any cohort study that examined the relationship between DM and the risk of gastric cancer incidence or mortality was eligible for inclusion in our study, and no restrictions were placed on language or publication status (published, in press, or in progress).The following search terms ("gastric" OR "stomach") AND ("carcinoma" OR "cancer" OR "neoplasm" OR "adenocarcinoma") AND ("diabetes" OR "diabetes mellitus") were searched (from inception to June 2016). The details of the search strategy are listed in Supplemental 1. Manual searches of the reference lists from all the relevant studies and review articles were conducted as well. The medical subject heading, methods, population status, design, exposure, and outcome variables of these articles were used to identify the relevant studies.

The literature search was independently undertaken by 2 authors using a standardized approach. Any inconsistencies between these 2 authors were settled by the primary author until a consensus was reached. The criteria for eligibility of the studies were as follows: (1) the study had to have a cohort design (prospective or retrospective); (2) the study investigated the association between DM and the risk of gastric cancer incidence or mortality; and (3) the study should report effect estimates (risk ratio [RR], hazard ratio [HR], standard incidence/ mortality ratio [SIR/SMR]) and 95\% confidence intervals (CIs) for comparisons of participants with DM and those without DM. We used the following exclusion criteria: (1) the type of study was non-cohort design; (2) the studies evaluated other factors such that the relationship between DM and gastric cancer was not available; and (3) the publications were duplicated studies, abstracts, reviews, or the reported data from an abstract or from a meeting.

\section{Data collection and quality assessment}

Studies were reviewed and data extracted independently by two authors using a pre-designed standard form. The following data were extracted from each study: the study group or first author's name, publication year, country, assessment of exposure, sample size, age at baseline, gender, percentage of participants overweight, gastric cancer cases, gastric cancer mortality cases, effect estimate, follow-up duration, and adjusted factors. For studies that reported several multivariable adjusted RRs, we selected the effect estimate that was maximally adjusted for potential confounders. Attempts were made to contact the authors for missing data.

The Newcastle-Ottawa Scale (NOS), which is quite comprehensive and has been partially validated for evaluating the quality of observational studies in metaanalysis, was used to evaluate methodological quality [39]. The NOS is based on the following 3 subscales: selection (4 items), comparability (1 item), and outcome (3 items). A "star system" (range, 0-9) has been developed for assessment (Table 1). The data extraction and quality assessment were conducted independently by 2 authors. Information was examined and adjudicated independently by an additional author referring to the original studies.

\section{Statistical analysis}

We examined the relationship between DM and risk of gastric cancer incidence or mortality on the basis of the effect estimate (RR, HR, SIR/SMR) and its $95 \%$ CI published in each study. If more than one, subsets were pooled by using a fixed effect model to calculate their RRs and $95 \%$ CIs for effect estimates of each study [40]. We 
used the random-effects model to calculate summary RRs and $95 \%$ CIs for participants with DM versus participants without DM [41]. We probed the association between DM and gastric cancer in men and women separately. Finally, the ratios of relative risk (RRRs) and the corresponding $95 \%$ CIs were used to calculate gender difference for the relationship between DM and gastric cancer incidence or mortality [42].

Heterogeneity between studies was investigated by using I-square and Q statistic, and were regarded as significant heterogeneity if the $P$ value was less than $0.10[43,44]$. Sensitivity analyses were also conducted to evaluate the impact of individual studies by systematically removing each individual study from the meta-analysis [45]. Subgroup analyses were conducted for gastric cancer incidence and mortality in men and women on the basis of country, age at baseline, effect estimate, follow-up duration, adjusted BMI, smoking, alcohol consumption, and physical activity or lack thereof. Interaction tests for differences between men and women in subsets were also calculated [46]. Several methods were employed to check for potential publication bias, including visual inspections of funnel plots for gastric cancer incidence and gastric cancer mortality and the Egger [47] and Begg [48] tests. All reported $P$ values are 2 -sided, and $P$ values less than 0.05 were regarded as statistically significant. Statistical analyses were performed using STATA software (version 12.0; Stata Corporation, College Station, TX, USA).

\section{ACKNOWLEDGMENTS}

This work was supported by the National Natural Science Foundation of China (No. 81272718, 81302125 and 81372550 ). The sponsors played no role in the study design, data collection, or analysis, or decision to submit the article for publication.

\section{CONFLICTS OF INTEREST}

No potential conflicts of interest were disclosed.

\section{REFERENCES}

1. Wild S, Roglic G, Green A, Sicree R, King H. Global prevalence of diabetes: estimates for the year 2000 and projections for 2030. Diabetes Care. 2004; 27:1047-53.

2. Centers for Disease Control and Prevention. 2011 National Diabetes Fact Sheet: National Estimates and General Information on Diabetes and Pre-diabetes in the United States. Atlanta: U.S. Department of Health and Human Services, Centers for Disease Control and Prevention; 2011.

3. International Diabetes Federation. Diabetes atlas. International Diabetes Federation; 2013.

4. Palmer SC, Mavridis D, Navarese E, Craig JC, Tonelli M, Salanti G, Wiebe N, Ruospo M, Wheeler DC, Strippoli GF.
Comparative efficacy and safety of blood pressure-lowering agents in adults with diabetes and kidney disease: a network meta-analysis. Lancet. 2015; 385:2047-56.

5. Mazzone T. Intensive glucose lowering and cardiovascular disease prevention in diabetes: reconciling the recent clinical trial data. Circulation. 2010; 122:2201-11.

6. Sarwar N, Gao P, Seshasai SR, Gobin R, Kaptoge S, Di Angelantonio E, Ingelsson E, Lawlor DA, Selvin E, Stampfer M, Stehouwer CD, Lewington S, Pennells L, et al, and Emerging Risk Factors Collaboration. Diabetes mellitus, fasting blood glucose concentration, and risk of vascular disease: a collaborative meta-analysis of 102 prospective studies. Lancet. 2010; 375:2215-22.

7. Song S, Wang B, Zhang X, Hao L, Hu X, Li Z, Sun S. Long-Term Diabetes Mellitus Is Associated with an Increased Risk of Pancreatic Cancer: A Meta-Analysis. PLoS One. 2015; 10:e134321.

8. Chen L, Li H, Gu L, Ma X, Li X, Gao Y, Zhang Y, Shen D, Fan Y, Wang B, Bao X, Zhang X. The Impact of Diabetes Mellitus on Renal Cell Carcinoma Prognosis: A MetaAnalysis of Cohort Studies. Medicine (Baltimore). 2015; 94:e1055.

9. Guraya SY. Association of type 2 diabetes mellitus and the risk of colorectal cancer: A meta-analysis and systematic review. World J Gastroenterol. 2015; 21:6026-31.

10. Zhou Y, Zhang X, Gu C, Xia J. Diabetes mellitus is associated with breast cancer: systematic review, metaanalysis, and in silico reproduction. Panminerva Med. 2015; 57:101-08.

11. Gong Y, Wei B, Yu L, Pan W. Type 2 diabetes mellitus and risk of oral cancer and precancerous lesions: a meta-analysis of observational studies. Oral Oncol. 2015; 51:332-40.

12. Tsilidis KK, Kasimis JC, Lopez DS, Ntzani EE, Ioannidis JP. Type 2 diabetes and cancer: umbrella review of metaanalyses of observational studies. BMJ. 2015; 350:g7607.

13. Jian Gang P, Mo L, Lu Y, Runqi L, Xing Z. Diabetes mellitus and the risk of prostate cancer: an update and cumulative meta-analysis. Endocr Res. 2015; 40:54-61.

14. Liao C, Zhang D, Mungo C, Tompkins DA, Zeidan AM. Is diabetes mellitus associated with increased incidence and disease-specific mortality in endometrial cancer? A systematic review and meta-analysis of cohort studies. Gynecol Oncol. 2014; 135:163-71.

15. Wideroff L, Gridley G, Mellemkjaer L, Chow WH, Linet M, Keehn S, Borch-Johnsen K, Olsen JH. Cancer incidence in a population-based cohort of patients hospitalized with diabetes mellitus in Denmark. J Natl Cancer Inst. 1997; 89:1360-65.

16. Jee SH, Ohrr H, Sull JW, Yun JE, Ji M, Samet JM. Fasting serum glucose level and cancer risk in Korean men and women. JAMA. 2005; 293:194-202.

17. Hemminki K, Li X, Sundquist J, Sundquist K. Risk of cancer following hospitalization for type 2 diabetes. Oncologist. 2010; 15:548-55. 
18. Lin SW, Freedman ND, Hollenbeck AR, Schatzkin A, Abnet CC. Prospective study of self-reported diabetes and risk of upper gastrointestinal cancers. Cancer Epidemiol Biomarkers Prev. 2011; 20:954-61.

19. Zendehdel K, Nyrén O, Ostenson CG, Adami HO, Ekbom A, Ye W. Cancer incidence in patients with type 1 diabetes mellitus: a population-based cohort study in Sweden. J Natl Cancer Inst. 2003; 95:1797-800.

20. Khan M, Mori M, Fujino Y, Shibata A, Sakauchi F, Washio M, Tamakoshi A, and Japan Collaborative Cohort Study Group. Site-specific cancer risk due to diabetes mellitus history: evidence from the Japan Collaborative Cohort (JACC) Study. Asian Pac J Cancer Prev. 2006; 7:253-59.

21. Adami HO, McLaughlin J, Ekbom A, Berne C, Silverman D, Hacker D, Persson I. Cancer risk in patients with diabetes mellitus. Cancer Causes Control. 1991; 2:307-14.

22. Tian T, Zhang LQ, Ma XH, Zhou JN, Shen J. Diabetes mellitus and incidence and mortality of gastric cancer: a meta-analysis. Exp Clin Endocrinol Diabetes. 2012; 120:217-23.

23. Ge Z, Ben Q, Qian J, Wang Y, Li Y. Diabetes mellitus and risk of gastric cancer: a systematic review and meta-analysis of observational studies. Eur J Gastroenterol Hepatol. 2011; 23:1127-35.

24. Ferlay J, Soerjomataram I, Dikshit R, Eser S, Mathers C, Rebelo M, Parkin DM, Forman D, Bray F. Cancer incidence and mortality worldwide: sources, methods and major patterns in GLOBOCAN 2012. Int $\mathrm{J}$ Cancer. 2015;136:E359-86.

25. Li L, Gan Y, Wu C, Qu X, Sun G, Lu Z. Coffee consumption and the risk of gastric cancer: a meta-analysis of prospective cohort studies. BMC Cancer. 2015; 15:733.

26. Han J, Jiang Y, Liu X, Meng Q, Xi Q, Zhuang Q, Han Y, Gao Y, Ding Q, Wu G. Dietary Fat Intake and Risk of Gastric Cancer: A Meta-Analysis of Observational Studies. PLoS One. 2015; 10:e138580.

27. Guo Y, Shan Z, Ren H, Chen W. Dairy consumption and gastric cancer risk: a meta-analysis of epidemiological studies. Nutr Cancer. 2015; 67:555-68.

28. Yang P, Zhou Y, Chen B, Wan HW, Jia GQ, Bai HL, Wu XT. Overweight, obesity and gastric cancer risk: results from a meta-analysis of cohort studies. Eur J Cancer. 2009; 45:2867-73.

29. National Task Force on the Prevention and Treatment of Obesity. Overweight, obesity, and health risk. Arch Intern Med. 2000; 160:898-904.

30. Yoon JM, Son KY, Eom CS, Durrance D, Park SM. Preexisting diabetes mellitus increases the risk of gastric cancer: a meta-analysis. World J Gastroenterol. 2013; 19:936-45.

31. Hidaka A, Sasazuki S, Goto A, Sawada N, Shimazu T, Yamaji T, Iwasaki M, Inoue M, Noda M, Tajiri H, Tsugane S, and JPHC Study Group. Plasma insulin, C-peptide and blood glucose and the risk of gastric cancer: the Japan
Public Health Center-based prospective study. Int J Cancer. 2015; 136:1402-10.

32. Tamakoshi A, Ozasa K, Fujino Y, Suzuki K, Sakata K, Mori M, Kikuchi S, Iso H, Sakauchi F, Motohashi Y, Tsuji I, Nakamura Y, Mikami H, et al, and JACC Study Group. Cohort profile of the Japan Collaborative Cohort Study at final follow-up. J Epidemiol. 2013; 23:227-32.

33. Pham TM, Fujino Y, Nakachi K, Suzuki K, Ito Y, Watanabe Y, Inaba Y, Tajima K, Tamakoshi A, Yoshimura T, and JACC Study Group. Relationship between serum levels of superoxide dismutase activity and subsequent risk of cancer mortality: findings from a nested case-control study within the Japan Collaborative Cohort Study. Asian Pac J Cancer Prev. 2009; 10 Suppl:69-73.

34. Pham TM, Fujino Y, Nakachi K, Suzuki K, Ito Y, Watanabe Y, Inaba Y, Tajima K, Tamakoshi A, Yoshimura T, and JACC Study Group. Relationship between serum levels of insulin-like growth factors and subsequent risk of cancer mortality: findings from a nested case-control study within the Japan Collaborative Cohort Study. Cancer Epidemiol. 2010; 34:279-84.

35. Pham TM, Fujino Y, Kikuchi S, Tamakoshi A, Matsuda S, Yoshimura T. Dietary patterns and risk of stomach cancer mortality: the Japan collaborative cohort study. Ann Epidemiol. 2010; 20:356-63.

36. Dixon JL, Copeland LA, Zeber JE, MacCarthy AA, Reznik SI, Smythe WR, Rascoe PA. Association between diabetes and esophageal cancer, independent of obesity, in the United States Veterans Affairs population. Dis Esophagus. 2016; 29:747-51.

37. Camargo MC, Freedman ND, Hollenbeck AR, Abnet CC, Rabkin CS. Height, weight, and body mass index associations with gastric cancer subsites. Gastric Cancer. 2014; 17:463-68.

38. Moher D, Liberati A, Tetzlaff J, Altman DG, and PRISMA Group. Preferred reporting items for systematic reviews and meta-analyses: the PRISMA statement. PLoS Med. 2009; 6:e1000097.

39. Wells G, Shea B, O'Connell D. The Newcastle-Ottawa Scale (NOS) for assessing the quality of nonrandomised studies in meta-analyses. Ottawa (ON): Ottawa Hospital Research Institute 2009. Available: http://www.ohri.ca/ programs/clinical_epidemiology/oxford.htm.

40. DerSimonian R, Laird N. Meta-analysis in clinical trials. Control Clin Trials. 1986; 7:177-88.

41. Ades AE, Lu G, Higgins JP. The interpretation of randomeffects meta-analysis in decision models. Med Decis Making. 2005; 25:646-54.

42. Huxley RR, Woodward M. Cigarette smoking as a risk factor for coronary heart disease in women compared with men: a systematic review and meta-analysis of prospective cohort studies. Lancet. 2011; 378:1297-305.

43. Deeks JJ, Higgins JP, Altman DG. Analysing Data and Undertaking Meta-Analyses. Cochrane Handbook for 
Systematic Reviews of Interventions. 2008; Chapter 9.

44. Higgins JP, Thompson SG, Deeks JJ, Altman DG. Measuring inconsistency in meta-analyses. BMJ. 2003; 327:557-60.

45. Tobias A. Assessing the influence of a single study in metaanalysis. Stata Tech Bull. 1999; 47:15-17.

46. Altman DG, Bland JM. Interaction revisited: the difference between two estimates. BMJ. 2003; 326:219.

47. Egger M, Davey Smith G, Schneider M, Minder C. Bias in meta-analysis detected by a simple, graphical test. BMJ. 1997; 315:629-34.

48. Begg CB, Mazumdar M. Operating characteristics of a rank correlation test for publication bias. Biometrics. 1994; 50:1088-101.

49. Coughlin SS, Calle EE, Teras LR, Petrelli J, Thun MJ. Diabetes mellitus as a predictor of cancer mortality in a large cohort of US adults. Am J Epidemiol. 2004; 159:1160-67.

50. Inoue M, Iwasaki M, Otani T, Sasazuki S, Noda M, Tsugane $\mathrm{S}$. Diabetes mellitus and the risk of cancer: results from a large-scale population-based cohort study in Japan. Arch Intern Med. 2006; 166:1871-77.

51. Chodick G, Heymann AD, Rosenmann L, Green MS, Flash S, Porath A, Kokia E, Shalev V. Diabetes and risk of incident cancer: a large population-based cohort study in Israel. Cancer Causes Control. 2010; 21:879-87.

52. Tseng $\mathrm{CH}$. Diabetes conveys a higher risk of gastric cancer mortality despite an age-standardised decreasing trend in the general population in Taiwan. Gut. 2011; 60: 774e779.

53. Verlato G, Zoppini G, Bonora E, Muggeo M. Mortality from site-specific malignancies in type 2 diabetic patients from Verona. Diabetes Care. 2003; 26:1047-51.

54. Swerdlow AJ, Laing SP, Qiao Z, Slater SD, Burden AC, Botha JL, Waugh NR, Morris AD, Gatling W, Gale EA, Patterson CC, Keen H. Cancer incidence and mortality in patients with insulin-treated diabetes: a UK cohort study. Br J Cancer. 2005; 92:2070-75.

55. Kessler II. Cancer mortality among diabetics. J Natl Cancer Inst. 1970; 44:673-86.

56. Ogunleye AA, Ogston SA, Morris AD, Evans JM. A cohort study of the risk of cancer associated with type 2 diabetes. Br J Cancer. 2009; 101:1199-201.

57. Atchison EA, Gridley G, Carreon JD, Leitzmann MF, McGlynn KA. Risk of cancer in a large cohort of U.S. veterans with diabetes. Int J Cancer. 2011; 128:635-43.
58. Koskinen SV, Reunanen AR, Martelin TP, Valkonen T. Mortality in a large population-based cohort of patients with drug-treated diabetes mellitus. Am J Public Health. 1998; 88:765-70.

59. Ragozzino M, Melton LJ 3rd, Chu CP, Palumbo PJ. Subsequent cancer risk in the incidence cohort of Rochester, Minnesota, residents with diabetes mellitus. J Chronic Dis. 1982; 35:13-19.

60. Batty GD, Shipley MJ, Marmot M, Smith GD. Diabetes status and post-load plasma glucose concentration in relation to site-specific cancer mortality: findings from the original Whitehall study. Cancer Causes Control. 2004; 15:873-81.

61. Chen YL, Cheng KC, Lai SW, Tsai IJ, Lin CC, Sung FC, Lin CC, Chen PC. Diabetes and risk of subsequent gastric cancer: a population-based cohort study in Taiwan. Gastric Cancer. 2013; 16:389-96.

62. Best LG, García-Esquinas E, Yeh JL, Yeh F, Zhang Y, Lee ET, Howard BV, Farley JH, Welty TK, Rhoades DA, Rhoades ER, Umans JG, Navas-Acien A. Association of diabetes and cancer mortality in American Indians: the Strong Heart Study. Cancer Causes Control. 2015; 26:1551-60.

63. Xu HL, Tan YT, Epplein M, Li HL, Gao J, Gao YT, Zheng W, Shu XO, Xiang YB. Population-based cohort studies of type 2 diabetes and stomach cancer risk in Chinese men and women. Cancer Sci. 2015; 106:294-98.

64. Vigneri P, Frasca F, Sciacca L, Pandini G, Vigneri R. Diabetes and cancer. Endocr Relat Cancer. 2009; 16:110323.

65. Tseng CH. Diabetes, insulin use, and gastric cancer: a population-based analysis of the Taiwanese. J Clin Gastroenterol. 2013; 47:e60-64.

66. Tseng $\mathrm{CH}$, Tseng FH. Diabetes and gastric cancer: the potential links. World J Gastroenterol. 2014; 20:1701-11.

67. Tseng $\mathrm{CH}$. Metformin reduces gastric cancer risk in patients with type 2 diabetes mellitus. Aging (Albany NY). 2016; 8:1636-49. doi: 10.18632/aging.101019. 